\title{
The effect of postmortem pH decline rate on mitochondrial apoptosis and tenderness of bovine skeletal muscle during aging
}

\author{
Jibing Ma \\ Gansu Agricultural University \\ Qunli Yu \\ Gansu Agricultural University \\ Mingshan Han \\ Inner Mongolia Kerchin Cattle Industry Co., Ltd \\ Ling Han ( $\square$ hltgggyx@163.com ) \\ Gansu Agricultural University
}

\section{Research Article}

Keywords: $\mathrm{pH}$ decline rate, ROS, Mitochondrial apoptosis, Tenderness, Bovine muscle

Posted Date: November 22nd, 2021

DOI: https://doi.org/10.21203/rs.3.rs-1073715/v1

License: (c) (i) This work is licensed under a Creative Commons Attribution 4.0 International License. Read Full License 


\section{Abstract}

This study aimed to investigate the effect of postmortem $\mathrm{pH}$ decline rate on mitochondrial dysfunction-induced apoptosis and bovine muscle tenderness during aging. Protein denaturation, reactive oxygen species (ROS) levels, mitochondrial apoptosis factors, and shear force were assessed in bovine muscles with different $\mathrm{pH}$ decline rates. The results showed that compared to the slow group, fast $\mathrm{pH}$ decline in bovine muscle significantly increased sarcoplasmic protein denaturation at $6-12 \mathrm{~h}$ and mitochondrial ROS levels at $6-24 \mathrm{~h}(P<0.05)$, and in turn significantly accentuated mitochondrial dysfunction and cytochrome c oxidation levels $(P<0.05)$, resulting in caspase-3 activation, apoptosis, and reduced muscle shear force $(P<0.05)$. These results demonstrated that the fast postmortem $\mathrm{pH}$ decline enhanced mitochondrial apoptosis and bovine muscle tenderization by inducing ROS accumulation during aging.

\section{Introduction}

Tenderness is one of the most important factors that influence consumer satisfaction with meat and contribute to repeat purchases ${ }^{1,2}$. After slaughter, the occurring chemical and physical changes contribute to the development of muscle into the meat and promote muscle tenderization ${ }^{3}$. Among these factors, glycolysis is one of the most essential processes in the production of final meat quality, and the rate of glycolysis in the early postmortem period may have a significant impact on muscle tenderization progression ${ }^{4}$. The inconsistency in meat tenderness could be attributed to variations in the rate of $\mathrm{pH}$ reduction in the early postmortem period ${ }^{5,6}$. Previous reports have suggested that the bovine muscle with a low $\mathrm{pH}$ before the onset of rigor mortis was transformed into tender beef ${ }^{7,8}$. These results suggest that the rate of postmortem $\mathrm{pH}$ decline had an important influence on muscle tenderization.

Muscle tenderization is influenced by the extensive interactions of biochemical processes in carcasses during postmortem aging, which includes the hydrolysis of key myofibrillar proteins such as desmin, titin, and troponin- $\mathrm{T}^{9}$. The hydrolysis of myofibrillar protein is the result of the activation of endogenous proteases, such as calpains, cathepsins, and caspases ${ }^{10,11}$. For decades, mitochondrial apoptosis has been shown to play an important part in the breakdown of myofibrillar protein in muscle throughout aging ${ }^{12,13}$. In the mitochondrial apoptosis pathway, release of cytochrome $c$ from mitochondria provided the stimulus for caspase-9 activation through the association of apoptotic protein activator-1 (Apaf-1) and procaspase-9 in the cytoplasm, and subsequently activated caspase- 9 followed by caspase- 3 activation thus enhancing muscle tenderness ${ }^{14}$. This type of cell death was different from necrosis, it was a process of programmed death caused by a lack of intracellular energy ${ }^{15}$. Furthermore, previous research has demonstrated that cytoplasmic acidification caused apoptosis and caspase-3 activation, suggesting that cytoplasmic $\mathrm{pH}$ changes occur early in the induction of mitochondrial apoptosis-related pathways ${ }^{16}$. After slaughter and bleeding of the cattle, the oxygen supply to the muscle is disrupted, and the aerobic respiration in the cells is switched to anaerobic glycolysis, resulting in lactate accumulation, ATP hydrolysis, and subsequently muscle acidification ${ }^{17}$. During postmortem aging, a fall in $\mathrm{pH}$ may further promote mitochondrial dysfunction and lead to apoptosis in bovine muscle ${ }^{18,4}$. In a low pH milieu, Reshkin et al. ${ }^{19}$ discovered that various apoptosis-related enzymes, namely DNases and caspases, were activated. As a result, acidification causes mitochondrial apoptosis in muscle cells. However, there is still a lack of conclusive evidence connecting pH decline rate to mitochondrial apoptosis in postmortem muscle.

Thus, in the present work, the bovine carcasses of various $\mathrm{pH}$ in the early postmortem phase were selected to investigate the influence of $\mathrm{pH}$ decline rate on mitochondrial apoptosis and muscle tenderness during aging. We aimed to clarify the mechanism of postmortem pH regulating muscle tenderness from the mitochondrial apoptosis pathway by analyzing protein denaturation temperature, Ros levels, mitochondrial apoptosis factors, myofibrillar fragmentation index (MFI), and shear force in different $\mathrm{pH}$ decline rates groups of bovine muscles.

\section{Results And Discussion}

Changes in $\mathrm{pH}$ of bovine muscle during postmortem aging. The $\mathrm{pH}$ of bovine muscle with different $\mathrm{pH}$ decline rates during postmortem aging is shown in Fig. 1. The $\mathrm{pH}$ of the fast $\mathrm{pH}$ decline group decreased significantly at $24 \mathrm{~h}$ while the $\mathrm{pH}$ of the slow group decreased significantly at $48 \mathrm{~h}$ compared with $0.5 \mathrm{~h}(P<0.05)$. However, the $\mathrm{pH}$ in the fast group was lower than the slow group by $4.06 \%, 5.11 \%, 8.34 \%, 4.43 \%$, and $2.67 \%$ at $0.5,2$, 6,12 , and $24 \mathrm{~h}(P<0.05)$, respectively. These findings suggest a significant difference in $\mathrm{pH}$ decline rates between the two groups within $24 \mathrm{~h}$ postmortem

After slaughter and bleeding, glycogen metabolism shifts from aerobic to anaerobic and the metabolite lactate accumulates, resulting in a decline in muscle $\mathrm{pH}^{24,25}$. Apaoblaza et al. ${ }^{26}$ demonstrated that the ultimate $\mathrm{pH}$ of carcasses was correlated with glycogen content and a sufficient amount of glycogen can supply the necessary fuel for the $\mathrm{pH}$ decrease. Previous studies have shown that the breakdown of ATP produced by postmortem muscle glycolysis led to the accumulation of protons $\left(\mathrm{H}^{+}\right)$, which was also caused a decrease in $\mathrm{pH}^{27}$. The rate of glycolysis is determined by the activity of glycolytic enzymes. Pyruvate kinase, enolase 2, phosphoglucomutase 1, fructose diphosphate aldolase, and enolase 3 are all phosphorylation-regulated enzymes that may be implicated in postmortem muscle glycolysis ${ }^{28}$. In addition, several other pre- and post-mortem factors might affect postmortem muscle glycolysis, such as genetics, pre-slaughter stress, carcass temperature, and S-nitrosylation of glycolytic enzymes, etc. ${ }^{26,29,30}$. In the present study, the fast group of muscles may have consumed glycogen more quickly, resulting in a low pH in the early postmortem period. 
Effect of $\mathrm{pH}$ decline rate on protein denaturation and mitochondrial ROS accumulation in postmortem bovine muscle. The decrease in pH is generally thought to induce further protein denaturation in muscle. Therefore, we evaluated the influence of pH decline rate on muscle protein denaturation temperature and ROS levels. A total of three heat absorption peaks were observed in the muscle tissue by DSC scanning, representing the denaturation temperature of the myosin head, sarcoplasmic protein, and actin ${ }^{31}$. The denaturation temperature of a protein increases when its structure is slightly altered. As shown in Table 1, both myosin and sarcoplasmic protein denaturation temperatures increased significantly in both groups during postmortem aging $(P<0.05)$, however myosin denaturation temperature in the fast group was $2.60 \%$ higher than in the slow group at $12 \mathrm{~h}(P<0.05)$. Sarcoplasmic protein denaturation temperature was $1.79 \%$ and $1.39 \%$ higher than in the slow group at 6 and $12 \mathrm{~h}$, respectively $(P<0.05)$. However, actin did not show any differences in denaturation temperature during the postmortem aging in the two groups. In addition, the fluorescence images of ROS in two groups are shown in Fig. 2A. The average fluorescence values of ROS in muscle cells, reflecting the ROS levels, were significantly higher in the fast group than the slow group at $6-24 \mathrm{~h}$ postmortem $(P<0.05$; Fig. $2 \mathrm{~B})$, with a most significant difference at $12 \mathrm{~h}$ $(P<0.01)$. The above results suggested that fast $\mathrm{pH}$ decline promoted myosin and sarcoplasmic protein denaturation and $\mathrm{ROS}$ accumulation in the postmortem muscle.

Insufficient ATP production and supply in the postmortem muscle in conjunction with the reduction of pH disrupt the normal redox system, leading to the accumulation of proapoptotic free radicals such as ROS ${ }^{13,14}$. There is a direct correlation between increased ROS levels and lower muscle $\mathrm{pH}^{32}$. Previous studies have shown that the antioxidant enzymes such as SOD, CAT, and GSH-Px showed decreased activity at the low pH in postmortem bovine muscle ${ }^{33}$. Sun et al. ${ }^{34}$ showed that an ultimate $\mathrm{pH}$ of 5.3-5.6 during postmortem muscle aging did not indicate that muscle glycogen was depleted, but rather that the inactivation of enzymes in the glycolytic pathway caused the reaction to halt when the pH fell below a certain threshold. These findings suggest that lower muscle pH induces a decrease in enzyme activity in the cytoplasm. The enzymes in the cytoplasm generally play an essential role in a neutral environment. Lower pH caused the active core group of the enzyme to deviate from its optimal dissociation state, reducing its capacity to bind to the substrate and catalytic activity ${ }^{25,35}$. In the present study, the fast pH decline group had greater ROS levels than the slow group, which could be owing to changes in the structure and activity of ROS scavenging enzymes by rapidly declining muscle $\mathrm{pH}$. Taken together, it was clear that postmortem fast $\mathrm{pH}$ decline contributed to the accumulation of muscle ROS by inducing sarcoplasmic protein denaturation.

Table 1

Changes in the denaturation peak temperature of Myosin $\left(T_{\text {Myosin }}\right)$, Myoplasmic protein $\left(T_{\text {Myoplasmic protein }}\right)$ and Actin ( $\left.T_{\text {Actin }}\right)$ in bovine muscles of different glycolytic rates at $0.5,6,12,24,72,120$, and $168 \mathrm{~h}$ postmortem.

\begin{tabular}{|c|c|c|c|c|c|c|c|c|}
\hline \multirow[t]{2}{*}{ Indicators } & \multirow{2}{*}{$\begin{array}{l}\text { Glycolytic } \\
\text { rate }\end{array}$} & \multicolumn{7}{|c|}{ Postmortem aging time } \\
\hline & & $0.5 \mathrm{~h}$ & $6 \mathrm{~h}$ & $12 \mathrm{~h}$ & $24 \mathrm{~h}$ & $72 \mathrm{~h}$ & $120 \mathrm{~h}$ & $168 \mathrm{~h}$ \\
\hline \multirow[t]{2}{*}{$\mathrm{T}_{\text {Myosin }}\left({ }^{\circ} \mathrm{C}\right)$} & Fast & $51.85 \pm 1.23^{\mathrm{B}}$ & $51.81 \pm 1.78^{\mathrm{B}}$ & $52.91 \pm 1.54^{A B^{*}}$ & $52.93 \pm 1.51^{\mathrm{AB}}$ & $53.18 \pm 1.39^{A B}$ & $53.68 \pm 1.45^{\mathrm{A}}$ & $53.67 \pm 1.39^{A}$ \\
\hline & Slow & $51.73 \pm 1.34^{\mathrm{b}}$ & $51.63 \pm 1.36^{b}$ & $51.53 \pm 1.43^{b}$ & $52.89 \pm 1.29^{a b}$ & $53.62 \pm 1.56^{a}$ & $53.81 \pm 1.48^{a}$ & $53.45 \pm 1.35^{a}$ \\
\hline \multirow{2}{*}{$\begin{array}{l}\mathrm{T}_{\text {Myoplasmic }} \\
\text { protein }\left({ }^{\circ} \mathrm{C}\right)\end{array}$} & Fast & $61.38 \pm 1.44^{\mathrm{B}}$ & $62.64 \pm 1.73^{A B^{*}}$ & $63.21 \pm 1.33^{A^{*}}$ & $63.64 \pm 1.39^{A}$ & $63.51 \pm 1.26^{\mathrm{A}}$ & $63.38 \pm 1.08^{A}$ & $63.33 \pm 1.36^{A}$ \\
\hline & Slow & $61.46 \pm 1.36^{c}$ & $61.54 \pm 1.47^{c}$ & $62.35 \pm 1.36^{b}$ & $63.39 \pm 1.28^{a}$ & $63.24 \pm 1.04^{\mathrm{a}}$ & $63.61 \pm 1.27^{a}$ & $63.40 \pm 1.63^{a}$ \\
\hline \multirow[t]{2}{*}{$\mathrm{T}_{\text {Actin }}\left({ }^{\circ} \mathrm{C}\right)$} & Fast & $76.43 \pm 0.75^{\mathrm{A}}$ & $76.61 \pm 0.58^{\mathrm{A}}$ & $76.31 \pm 0.57^{A}$ & $77.53 \pm 0.61^{\mathrm{A}}$ & $77.47 \pm 0.65^{\mathrm{A}}$ & $76.88 \pm 0.59^{A}$ & $76.59 \pm 0.78^{A}$ \\
\hline & Slow & $76.51 \pm 0.66^{a}$ & $77.03 \pm 0.65^{a}$ & $76.53 \pm 0.65^{a}$ & $77.56 \pm 0.72^{a}$ & $77.18 \pm 0.98^{a}$ & $77.67 \pm 0.54^{\mathrm{a}}$ & $76.42 \pm 0.68^{a}$ \\
\hline
\end{tabular}

Effect of pH decline rate on mitochondrial dysfunction and cytochrome c redox state. A mitochondrial dysfunction is a precursor to cell apoptosis. Therefore, the effect of $\mathrm{pH}$ decline rate on mitochondrial membrane permeability and cytochrome $\mathrm{c}$ redox state were assessed. Fig. $3 \mathrm{~A}$ showed that the mitochondrial membrane permeability significantly increased during postmortem aging in both groups $(P<0.05)$ and significantly higher in the fast group by $14.05 \%, 22.39 \%, 18.34 \%$ and $25.28 \%$ than in the slow group at $6,12,24$ and $72 \mathrm{~h}$, respectively $(P<0.05)$. The cytochrome $c$ reduction levels are shown in Fig. 3B. Our results showed that cytochrome c reduction levels decreased significantly postmortem in both two groups $(P<0.05)$. Furthermore, the cytochrome c reduction in the fast group was significantly lower than the slow group by $16.71 \%, 23.39 \%, 17.05 \%$, and $26.61 \%$ at 6 , 12,24 , and $120 \mathrm{~h}$, respectively $(P<0.05)$, indicating that fast $\mathrm{pH}$ decline induced mitochondrial membrane dysfunction and cytochrome $\mathrm{c}$ oxidation during the postmortem aging.

ROS, produced in mitochondria, was an additional indicator for mitochondrial apoptosis ${ }^{36}$. The weakening of antioxidant enzymes and other defense systems in postmortem muscle inevitably led to the production of ROS ${ }^{37}$. Excessive accumulation of ROS induced swelling and destruction of mitochondria membrane and ultimately mediated mitochondrial apoptosis ${ }^{14,38}$. ROS could attack the mitochondrial membrane polyunsaturated fatty acids to produce lipid peroxides such as malondialdehyde, causing mitochondrial swelling and increasing mitochondrial membrane 
permeability ${ }^{13,39}$. Moreover, ROS induced cytoplasmic $\mathrm{Ca}^{2+}$ influx into mitochondria, leading to mitochondrial $\mathrm{Ca}^{2+}$ overload, which further caused an increase in mitochondrial membrane pore opening and permeability ${ }^{40}$. Subsequently, the release of cytochrome $c$ from damaged mitochondria into the cytoplasm was a universal event for mitochondrial apoptosis ${ }^{41}$, but its catalytic activity was largely dependent on its oxidative state ${ }^{14}$. Suto et al. ${ }^{42}$ also showed that the oxidized cytochrome $\mathrm{c}$ was more effective in initiating mitochondrial apoptosis. In the present study, fast pH decline facilitated cytochrome c oxidation. Previous studies have showed that the oxidation of cytochrome $\mathrm{c}$ was associated with mitochondrial oxidants, such as $\mathrm{H}_{2} \mathrm{O}_{2}{ }^{37,43}$. Together with the above findings on the role of $\mathrm{pH}$ decline rate in ROS, it suggested that fast $\mathrm{pH}$ decline indirectly induced mitochondrial dysfunction and cytochrome c oxidation by promoting the accumulation of mitochondrial ROS.

Effect of pH decline rate on caspase-3, apoptosis and tenderness in bovine muscle. To further exam the downstream events of cytochrome $\mathrm{c}$ oxidation and mitochondrial dysfunction, the effect of $\mathrm{pH}$ decline rate on caspase-3 activity, apoptotic nucleus, $\mathrm{MFI}$, and shear force were evaluated during postmortem aging. As depicted in Fig. 4, in both two groups, caspase-3 activity tended to increase initially and later decrease ( $P<0.05)$, with caspase-3 activity reaching the peak at $24 \mathrm{~h}$. Besides, the caspase-3 activity in the fast group was significantly higher than the slow group at $12-$ $168 \mathrm{~h}(P<0.05)$, except the $72 \mathrm{~h}$ time point. TUNEL assay of the apoptotic nucleus is shown in Fig. 5A. The normal nucleus was labeled with overall blue fluorescence (DAPI), while the apoptotic nucleus was labeled with green fluorescence (TUNEL positive). The proportion of apoptotic nuclei of the total nuclei was quantified and shown in Fig. 5B, with a significant increase in the total number of apoptotic nuclei in both groups $(P<0.05)$. In the fast group, the total apoptotic nuclei were significantly higher than those in the slow group at 24-168 h $(P<0.05)$.

The number of the MFI reflects the degree of fragmentation of myofibrils and positively correlates with the degradation of myofibrillar proteins. Table 2 showed a significant increase in MFI during aging for both groups $(P<0.05)$, however, the fast group had a significantly higher MFI than the slow group at $12-168 \mathrm{~h}(P<0.05)$. Shear force was used to evaluate the tenderness of bovine muscle, and the smaller the value indicates the tenderer of the muscle. As shown in Table 2, the shear force of both fast and slow groups kept growing until $12 \mathrm{~h}(P<0.05)$. However, it plummeted at 24-168 $\mathrm{h}(P<0.05)$. In the fast group, the shear force was significantly higher than in the slow group at $6 \mathrm{~h}(P<0.05)$, but significantly lower than in the slow group at $12-168 \mathrm{~h}(\mathrm{P}<0.05)$ and $10.49 \%$ lower than in the slow group at $168 \mathrm{~h}$. The above results suggested that fast $\mathrm{pH}$ decline promoted caspase-3 activation, apoptosis, and bovine muscle tenderization during postmortem aging.

Caspase-3 is one of the most important effector caspases in the apoptotic pathway and plays a critical role in muscle tenderization ${ }^{44}$. The oxidized cytochrome $c$ interacts rapidly with apoptotic protease activating factor (Apaf-1) and procaspase-9 in the presence of dATP to activate caspase-9, which further activates the downstream effector caspase- $3^{12,13,41}$. The results of this study indicated that the caspase-3 showed the highest activity at $24 \mathrm{~h}$ time point. Our finding was confirmed by previous reports ${ }^{45}$, in which they suggested that caspase-3 activity in bovine skeletal muscle gradually increased to a maximum at approximately $24 \mathrm{~h}$ time point. Besides, our study also showed that the caspase-3 activity in the fast group was higher than that in the slow group. Combining the above effect of $\mathrm{pH}$ decline rate on ROS accumulation, mitochondrial dysfunction, and cytochrome c oxidation, we concluded that the fast $\mathrm{pH}$ decline promoted postmortem caspase-3 activation and apoptosis in the bovine muscle.

Postmortem muscle tenderization is a complex biochemical process involving the degradation of myofibrillar proteins and is controlled by a variety of protein hydrolases, including caspase-3 and calpain- $\mathbf{1}^{46}$. According to Kemp and Parr ${ }^{47}$, the formation of 28- and 30-kDa troponin-T degradation products and the degradation of desmin improved the muscle tenderness. Although these proteins were more likely to be recognized by calpain-1, caspase-3 also played an important role in this process. Huang et al. ${ }^{41}$ reported that caspase-3 also recognized and interacted with actomyosin, titin, nebulin, and tropomyosin in myofibrillar protein and this interaction can trigger further hydrolysis. As a result, caspase-3 is vital in enhancing the tenderness of bovine muscle during aging. In the present study, the bovine muscle tenderness was higher in the fast $\mathrm{pH}$ decline group than in the slow group at 12-168 $\mathrm{h}$ postmortem and matched the caspase-3 activity. Hwang and Thompson ${ }^{7}$ found that bovine longissimus dorsi with lower pH before the onset of rigour mortis produced more tender meat in the later stages of aging, which backed up the current findings. Given the essential role of $\mathrm{pH}$ decline rate in caspase- 3 activation, it is possible that fast $\mathrm{pH}$ decline increases bovine muscle tenderization via the mitochondrial apoptotic pathway. Our experiment also observed that the tenderness of the fast group was lower than that of the slow group at $6 \mathrm{~h}$ postmortem, which could be associated to calpain-1 activity. Previous research has revealed that calpain-1 activation occurred around $6 \mathrm{~h}$ postmortem in bovine muscle ${ }^{48}$, and that calpain-1 degradation activity on the myofibrillar protein was strongest at $\mathrm{pH} 7.5^{49}$. Lomiwesa et al. ${ }^{50}$ concluded that although calpain-1 autolysis was fast at a low pH, the hydrolysis of myofibrillar proteins was diminished in pork muscle. Despite the fact that no experiments involving calpain-1 activity were conducted in this study, it can be hypothesized, based on previous studies, that the fast $\mathrm{pH}$ decline group may have decreased calpain-1 activity at $6 \mathrm{~h}$ due to the lower $\mathrm{pH}$ microenvironments. Therefore, various processes other than mitochondrial apoptosis may also be involved in the regulation of postmortem $\mathrm{pH}$ decline rate on bovine muscle tenderness during aging, and this needs to be investigated further in the future. The current study is simply a first step towards understanding the role of postmortem pH in muscle tenderization during aging and we believe our findings will encourage more research in this field. 
Table 2

Changes in the myofibril fragmentation index (MFI) and shear force in bovine muscles of different glycolytic rates at $0.5,6,12,24,72,120$, and 168 h postmortem.

\begin{tabular}{|c|c|c|c|c|c|c|c|c|}
\hline \multirow[t]{2}{*}{ Indicators } & \multirow{2}{*}{$\begin{array}{l}\text { Glycolytic } \\
\text { rate }\end{array}$} & \multicolumn{7}{|c|}{ Postmortem aging time } \\
\hline & & $0.5 \mathrm{~h}$ & $6 \mathrm{~h}$ & $12 \mathrm{~h}$ & $24 \mathrm{~h}$ & $72 \mathrm{~h}$ & $120 \mathrm{~h}$ & $168 \mathrm{~h}$ \\
\hline \multirow[t]{2}{*}{ MFI } & Fast & $64.07 \pm 7.11^{\mathrm{F}}$ & $65.13 \pm 6.53^{\mathrm{F}^{*}}$ & $108.67 \pm 5.52^{\mathrm{E}^{\star}}$ & $125.60 \pm 7.63^{D^{*}}$ & $142.53 \pm 6.11^{C^{*}}$ & $167.40 \pm 6.77^{\mathrm{B}^{\star}}$ & $183.47 \pm 7.04^{\mathrm{A}^{*}}$ \\
\hline & Slow & $66.07 \pm 6.03^{g}$ & $79.06 \pm 6.80^{f}$ & $93.53 \pm 6.11^{\mathrm{e}}$ & $108.73 \pm 7.71^{d}$ & $128.72 \pm 6.74^{c}$ & $149.33 \pm 7.63^{b}$ & $166.87 \pm 6.93^{a}$ \\
\hline \multirow{2}{*}{$\begin{array}{l}\text { Shear } \\
\text { force } \\
\text { (kgf) }\end{array}$} & Fast & $6.62 \pm 0.37^{D}$ & $7.79 \pm 0.53^{B^{*}}$ & $8.45 \pm 0.33^{A^{*}}$ & $7.18 \pm 0.42^{C^{*}}$ & $6.07 \pm 0.40^{E^{*}}$ & $5.61 \pm 0.52^{\mathrm{EF} *}$ & $5.12 \pm 0.31^{\mathrm{F}^{*}}$ \\
\hline & Slow & $6.53 \pm 0.63^{d}$ & $7.20 \pm 0.39^{c}$ & $8.96 \pm 0.35^{a}$ & $7.74 \pm 0.37^{b}$ & $6.91 \pm 0.41^{\mathrm{cd}}$ & $6.24 \pm 0.34^{\text {de }}$ & $5.72 \pm 0.35^{e}$ \\
\hline
\end{tabular}

A-B: Each letter denotes a statistically significant difference in the fast group at different postmortem times $(P<0.05)$. a-c: Each letter denotes a statistically significant difference in the slow group at different postmortem times $(P<0.05)$. * indicates the significance compared the same time points between two groups $(P<0.05)$. All measurements were expressed as the mean $\pm \mathrm{SE}$.

\section{Materials And Methods}

Muscle sampling and preparation. Fifty crossbred bulls (Luxi yellow cattle $\times$ Simmental) aged 24 to 36 months with a bodyweight of $450 \pm 50 \mathrm{~kg}$ were randomly chosen from Gansu Kangmei Modern Agriculture and Animal Husbandry Industry Group Co., Ltd. (Linxia City, Gansu province, China). The protocol and procedures used were reviewed and approved by the Operating Procedures of Cattle Slaughter in the National Standards of China. The Longissimus thoracis in the left side of carcases were removed after slaughter and stored at $4^{\circ} \mathrm{C}$. The pH of the muscles were measured at 0.5 , $2,6,12,24,48$, and $72 \mathrm{~h}$ during aging. Based on the muscle $\mathrm{pH}$ at $0.5 \mathrm{~h}$ (Noted as $\mathrm{pH} 0.5 \mathrm{~h}$ ) and $6 \mathrm{~h}$ (Noted as pH6h) postmortem, muscle samples from 12 carcasses were selected and divided into 2 groups (6 per group): a fast decreasing pH group (Noted as a fast group with pH6h < 5.8) and a slow decreasing $\mathrm{pH}$ group (Noted as a slow group with $\mathrm{pH} 6 \mathrm{~h}>6.2)^{20}$. The time point for each sample storage was $0.5,6,12,24,72,120$, and $168 \mathrm{~h}$ at $4^{\circ} \mathrm{C}$, at which samples were collected and the muscle's shear force was measured immediately. A portion of samples was stored in liquid nitrogen for biochemical indicators analysis.

Determination of the muscle $\mathrm{pH}$. pH was measured using a portable pH meter (Testo® 230 meter, Testo GmbH \& Co., Lenzkirch, Germany). The electrode was calibrated with standard buffer solutions at 4.0 and $7.0 \mathrm{pH}$ values (Mallinckrodt Chemicals, Phillipsburg, NJ, USA). The electrode was placed into the muscle at random locations throughout the muscle for measurement. Before the next measurement, the electrode probe was cleaned with ultrapure water $(\mathrm{pH} 7.0)$ and wiped dry with filter paper. Each sample was measured three times.

Differential Scanning Calorimetry (DSC) analysis. A PerkinElmer differential scanning calorimeter (Waltham, USA) was used to analyze the denaturation temperature of bovine muscle. Minced muscle tissue $\left(10-15 \mathrm{mg}\right.$ ) was enclosed in an aluminum box and heated from $20^{\circ} \mathrm{C}$ to $100^{\circ} \mathrm{C}$ at a rate of $3^{\circ} \mathrm{C} / \mathrm{min}$, using the sealed empty box as a reference. Denaturation temperature $\left(T,{ }^{\circ} \mathrm{C}\right)$ was calculated by Pyris-12 software (Perkin ElmerInstruments, USA).

Determination of reactive oxygen species (ROS). Muscle ROS levels were determined according to a previously described method ${ }^{21}$ with some modifications. Briefly, muscle samples were fixed in $4 \%$ paraformaldehyde for $48 \mathrm{~h}$ and were trimmed, dehydrated in ethanol, followed by embedded in paraffin before being section into $4.0 \mu \mathrm{m}$ thickness tissue slices. Tissue slices were dewaxed in xylene and anhydrous ethanol for 10 min, respectively. After being washed with PBS buffer $\left(\mathrm{pH} \mathrm{7.2)}\right.$, the sections were incubated in $5 \mu \mathrm{mol} / \mathrm{L} \mathrm{DCFH-DA}$ at $37^{\circ} \mathrm{C}$ for $60 \mathrm{~min}$ protected from light and were subsequently washed off with PBS. Finally, the slices were sealed with an anti-fluorescence quenching sealer and placed under a fluorescence microscope (CKX31, Olympus, Japan) for observation ( $E x=490 \mathrm{~nm}$ and $E m=520 \mathrm{~nm}$ ). Sections were scanned (400x) by a panoramic scanner (CaseViewer 2.4, Hungary) and the average fluorescence intensity of each cell cross-section was analyzed using the Halo v3.0.311.314 software (Indicalabs, USA).

Extraction of muscle mitochondria. The extraction of mitochondrial and cytoplasmic proteins from muscle tissue was followed as a previously described method ${ }^{22}$. In brief, approximately $5.0 \mathrm{~g}$ of muscle samples were mixed with $50 \mathrm{~mL}$ of mitochondrial separation medium (1 mmol/L EDTA, $300 \mathrm{mmol} / \mathrm{L}$ sucrose, $0.5 \%$ bovine serum albumin, $15 \mathrm{mmol} / \mathrm{L}$ Tris, $\mathrm{pH} 7.2$ ) and homogenized in an ice bath. The homogenate was centrifuged at $4^{\circ} \mathrm{C}$ at $1,000 \times g$ for $10 \mathrm{~min}$. The obtained supernatant was centrifuged at $4^{\circ} \mathrm{C}$ at $8,000 \times \mathrm{g}$ for 20 min. The supernatant contained the cytoplasmic protein in solution while the precipitate was then extracted in mitochondria. The resulting precipitate was mixed with buffer (containing $300 \mathrm{mmol} / \mathrm{L}$ sucrose, $1 \mathrm{mmol} / \mathrm{L}$ EDTA, $15 \mathrm{mmol} / \mathrm{L}$ Tris, $\mathrm{pH}$ 7.2) to serve as the mitochondrial solution. The biuret method was employed to measure the final protein concentration and the bovine serum albumin (Sigma Chemical Co., St. Louis, MO) was used as a standard.

Determination of mitochondrial membrane permeability. Mitochondrial membrane permeability was measured according to a previously described method $^{13}$. The concentration of the mitochondrial solution was adjusted to $2 \mathrm{mg} / \mathrm{mL}$ and incubated with four times of volumes of cold test medium (including $250 \mathrm{mmol} / \mathrm{L}$ sucrose, $10 \mathrm{mmol} / \mathrm{L}$ Tris- $\mathrm{HCl}, \mathrm{pH}$ 7.4) at room temperature for $3 \mathrm{~min}$. Mitochondrial membrane permeability was determined 
by analyzing the light absorption value of the mixed solution with a UV spectrophotometer at $520 \mathrm{~nm}$. The lower absorbance indicated the higher mitochondrial permeability.

Determination of cytochrome $\mathrm{c}$ redox state. The method to determine cytochrome $\mathrm{c}$ redox was based on a previously described method ${ }^{24}$ with minor modifications. Approximately $4.0 \mathrm{~g}$ of chopped muscle tissue was homogenized in $16.0 \mathrm{~mL}$ of cold separation buffer ( $0.3 \mathrm{~mol} / \mathrm{L}$ sucrose, $0.5 \%$ bovine serum albumin, $1 \mathrm{mmol} / \mathrm{L}$ EDTA, $0.01 \mathrm{~mol} / \mathrm{L}$ Tris- $\mathrm{HCl}, \mathrm{pH} 7.4$ ) and centrifuged at $4{ }^{\circ} \mathrm{C}$ at $1,000 \times g$ for $10 \mathrm{~min}$. After that, the supernatant was centrifuged at $4{ }^{\circ} \mathrm{C}$ at $8,000 \times g$ for $15 \mathrm{~min}$. The cytochrome $\mathrm{c}$ reduction levels were measured as the absorbance value of the obtained supernatant at $550 \mathrm{~nm}$ minus the absorbance value at $535 \mathrm{~nm}$ then divided by total protein concentration $\left(\Delta \mathrm{A}_{550-535} / \mathrm{mg}\right.$ protein). The biuret method was employed to measure the final protein concentration and the bovine serum albumin (Sigma Chemical Co., St. Louis, MO) was used as a standard.

Determination of caspase activity. A caspase-3 activity assay kit (Sigma-Aldrich, USA) was employed to determine its activity. In short, samples (1.0 g) were lysed in a precooled lysis solution ( $1 \mathrm{mmol} / \mathrm{L}$ dithiothreitol, $100 \mathrm{mmol} / \mathrm{L}$ Hepes, $0.1 \% \mathrm{NP}-40$ and $10 \%$ sucrose, $\mathrm{pH} 7.5)$ Samples were then smashed by employing a glass pestle and mortar 30 times under ice, and then the mixtures were centrifuged at $12,000 \times g$ for 10 min. Subsequently, $45 \mu \mathrm{L}$ of $10 \mathrm{mmol} / \mathrm{L}$ dithiothreitols and $5 \mu \mathrm{L}$ of $4 \mathrm{mmol} / \mathrm{L}$ DEVD-pNA substrate were added into $20 \mu \mathrm{L}$ of sample aliquots. Then the mixed solution was incubated at $37^{\circ} \mathrm{C}$ for $1 \mathrm{~h}$ and a fluorescence spectrophotometer (Shimadzu RF 5301, Kyoto, Japan) was used to measure the fluorescent intensity of the sample (Ex=360 $\mathrm{nm}$ and $\mathrm{Em}=460 \mathrm{~nm})$.

Determination of apoptotic nucleus. TdT-mediated dUTP nick-end labeling (TUNEL) assay was used to detect the apoptotic nucleus. Muscle samples were cut into a block of $1.0 \mathrm{~cm} \times 0.5 \mathrm{~cm} \times 0.5 \mathrm{~cm}$ and fixed in a $4 \%$ paraformaldehyde solution for more than $48 \mathrm{~h}$. Samples were paraffin-embedded and cut into ten $\mu \mathrm{m}$-thickness tissue sections and transferred onto slides. After dewaxing and rehydration, the sections were immersed with formaldehyde solution containing $3 \% \mathrm{H}_{2} \mathrm{O}_{2}$ to remove endogenous peroxidase. The sections were permeabilized by immersing them in a solution containing $0.1 \% \mathrm{Na}_{2} \mathrm{NO}_{3}$ and $0.1 \%$ Triton X-100. The permeabilized tissue sections were rinsed and washed with buffer (137 mmol/L NaCl, 4.3 $\mathrm{mmol} / \mathrm{L}$ disodium phosphate, $2.7 \mathrm{mmol} / \mathrm{L} \mathrm{KCl}, 1.4 \mathrm{mmol} / \mathrm{L}$ potassium dihydrogen phosphate, $\mathrm{pH}$ 7.4). After washing, the sections were blocked by $5 \%$ goat serum for $30 \mathrm{~min}$ and then washed with the above buffer for $30 \mathrm{~min}$. The labeling enzyme and the solution were prepared in a ratio of $1: 9$ to achieve the TUNEL reaction solution. The tissue sections were then covered with the solution prepared and incubated at $37^{\circ} \mathrm{C}$ for 60 min in a light protecting chamber. As for the negative controls, we used the lack of labeling enzyme during the TUNEL solution preparation. Positive controls were incubated with $5.0 \mathrm{U} / \mathrm{mL}$ DNase I for $10 \mathrm{~min}$ at room temperature before adding the TUNEL reaction solution. DAPI was added for nuclei staining, and the tissue sections were applied with glycerol and placed under a fluorescent microscope (CKX31, Olympus, Japan) for observation. Regular cell nuclei were stained in blue fluorescence by DAPI, and apoptotic cell nuclei were stained in green fluorescence by TUNEL. At least three fields of view per section were chosen and quantified for each sample (400x), and the apoptotic rate was calculated as the ratio of apoptotic nuclei to regular nuclei.

Determination of the myofibril fragmentation index (MFI). MFI was determined by the method as reported previously ${ }^{2}$. In short, $5.0 \mathrm{~g}$ of meat was added with $20 \mathrm{~mL}$ of MFI buffer $\left(100 \mathrm{mmol} / \mathrm{L} \mathrm{KCl}, 20 \mathrm{mmol} / \mathrm{L} \mathrm{K}_{3} \mathrm{PO}_{4}, 1 \mathrm{mmol} / \mathrm{L} \mathrm{EDTA}, 1 \mathrm{mmol} / \mathrm{L} \mathrm{MgCl}_{2}, 1 \mathrm{mmol} / \mathrm{L} \mathrm{NaN}_{3}, \mathrm{pH} 7.1\right)$ and homogenized on ice. The homogenate was then centrifuged at $4^{\circ} \mathrm{C}$ at $1000 \times g$ for $15 \mathrm{~min}$. After that, the supernatant was discarded. Next, $20 \mathrm{~mL}$ of $\mathrm{MFI}$ buffer was used to re-suspend the precipitate and the samples were homogenized again. The mixture was then centrifuged to discard the supernatant. Afterward, the precipitate was dissolved with $10 \mathrm{~mL}$ of MFI buffer, and was filtered through a 200-mesh nylon screen. Another $5 \mathrm{~mL}$ of MFI buffer was added to help the myofibrillar protein pass through the filter. Filter myofibrillar protein was quantified via the biuret method to determine its protein concentration, and its final concentration was achieved at $0.5 \mathrm{mg} / \mathrm{mL}$ via additional MFI buffer. A UV spectrophotometer was used to measure the absorbance at $540 \mathrm{~nm}$. The final value was obtained by multiplying the reading 200 times to represent the MFI.

Determination of the shear force. The shear force of bovine muscle was measured according to a previously described method ${ }^{14}$. The samples were cooked in a bag and submerged in water at $80^{\circ} \mathrm{C}$ until the central temperature reached above $70^{\circ} \mathrm{C}$ for 30 min. Subsequently, the meat samples were cooled to room temperature, and three to five meat columns ( $\Phi$ 1.27) were removed along the direction of the muscle fibers as representative samplers. Each sample was then cut by a blade perpendicular to the long axis of the muscle fibers and the shear force was measured by using a tenderness meter (C-LM4, Harbin, China).

Statistical analysis. The data were analyzed using IBM SPSS software 21.0 (SPSS, Inc., Chicago, IL, USA). The results were presented as mean \pm standard error (SE) from six biological replicates. The one-way analysis of variance (ANOVA) procedure followed by the Duncan's multiple range tests was used to separate the means. If $P<0.05$, the difference was significant. The student's t-test was employed to compare the differences in the means between the two groups $\left(* P<0.05,{ }^{*} P<0.01\right)$. The results were presented as mean \pm standard error (SE).

\section{Conclusion}

The present study investigated the effect of postmortem pH decline rates on mitochondrial apoptosis and tenderness in bovine muscle. The results demonstrate that the fast $\mathrm{pH}$ decline promoted sarcoplasmic protein denaturation and ROS accumulation, which further enhanced mitochondrial dysfunction and cytochrome c oxidation, thereby improving postmortem bovine skeletal muscle tenderness via caspase-3 activation. Therefore, the fast $\mathrm{pH}$ decline can increases bovine muscle tenderization by inducing mitochondrial apoptosis, and postmortem pH decline rates are important in

Page 6/12 
ultimate muscle tenderness development throughout aging. This new observation will provide scientific insight about the involvement of postmortem $\mathrm{pH}$ changes in apoptosis and beef tenderization.

\section{Declarations}

\section{Data availability}

The datasets generated during and/or analyzed during the current study are available from the corresponding author on reasonable request.

\section{Acknowledgments}

The authors would like to thank the special funds for the National Natural Science Foundation of China (Grant Nos. 31760482), Fostering Foundation for the Excellent Ph.D. Dissertation of Gansu Agricultural University (Grant Nos. YB2018003), and the Key Technology Innovation and Industrial Application of High Quality Cattle Quality Fattening and Green Processing (No.18YFINA075).

\section{Author contributions}

J.M., L.H., and Q.Y. conceived and designed the experiments. J.M. and M.H. performed the experiments. J.M., L.H. analyzed the data. Q.Y. contributed reagents, materials, and analysis tools. J.M. and L.H. wrote and revised the paper. All authors read and approved the final manuscript.

\section{Competing interests}

The authors declare no competing interests.

\section{References}

1. Kemp, C. M. \& Parr, T. The effect of recombinant caspase 3 on myofibrillar proteins in porcine skeletal muscle. Animal, 2, 1254-1264 https://doi.org/10.1017/S1751731108002310 (2008).

2. Dang, D. S. et al. Inhibition of mitochondrial calcium uniporter enhances postmortem proteolysis and tenderness in beef cattle. Meat Sci, 162 , 108039 https://doi.org/10.1016/j.meatsci.2019.108039 (2020).

3. Paredi, G., Raboni, S., Bendixen, E., de Almeida, A. M. \& Mozzarelli, A.. "Muscle to meat" molecular events and technological transformations: The proteomics insight.J Proteomics. 75,4275-4289. http://doi.org/10.1016/j.jprot.2012.04.011 (2012)

4. Honikel, K. O.. Conversion of muscle to meat glycolysis. Encyclopedia of meat sciences (pp. 353-357). (second ed.). Oxford:Academic Press. https://doi.org/10.1016/B0-12-464970-X/00127-6 (2014)

5. O'Halloran, G. R., Troy, D. J. \& Buckley, D. J. The relationship between early post-mortem pH and the tenderisation in beef muscles. Meat Sci, 45, 239-251 https://doi.org/10.1016/S0309-1740(96)00074-5 (1997).

6. Hannula, T. \& Puolanne, E. The effect of the cooling rate on beef tenderness: the significance of pH at $7{ }^{\circ} \mathrm{C} . \mathrm{Meat}$ Sci, $67,403-408$ https://doi.org/10.1016/j.meatsci.2003.11.012 (2004).

7. Hwang, I. H. \& Thompson, J. M. The interaction between $\mathrm{pH}$ and temperature decline early post-mortem on the calpain system and objective tenderness in electrically stimulated beef longissimus dorsi muscle. Meat Sci, 58, 167-174 https://doi.org/10.1016/S0309-1740(00)00147-9 (2001).

8. White, A., O’Sullivan, A., Troy, D. J. \& O’Neill, E. E. Manipulation of the pre-rigor glycolytic behaviour of bovine M. longissimus dorsi in order to identify causes of inconsistencies in tenderness. Meat Sci, 73, 151-156 https://doi.org/10.1016/j.meatsci.2005.11.021 (2006).

9. Huff-Lonergan, E., Zhang, W. G. \& Lonergan, S. M. Biochemistry of postmortem muscle-Lessons on mechanisms of meat tenderization. Meat Sci, 86, 184-195 https://doi.org/10.1016/j.meatsci.2010.05.004 (2010).

10. Huang, F. et al.. Changes in apoptotic factors and caspase activation pathways during the post-mortem aging of beef muscle.Food Chem. 190,110-114. http://doi.org/10.1016/j.foodchem.2015.05.056 ( 2016)

11. Zhang, J. Y., Ma, D. Y. \& Kim, Y. H. B.. Mitochondrial apoptosis and proteolytic changes of myofibrillar proteins in two different pork muscles during aging.Food Chem. 319,126571. https://doi.org/10.1016/j.foodchem.2020.126571 (2020).

12. Dorstyn, L., Read, S., Cakouros, D., Huh, J. R. \& Kumar, H. S. The role of cytochrome c in caspase activation in Drosophila melanogaster cells. J Cell Biol, 156, 1089-1098 https://doi.org/10.1083/jcb.200111107 (2002).

13. Zhang, J. Y. et al.. Study on the apoptosis mediated by cytochrome $c$ and factors that affect the activation of bovine longissimus muscle during postmortem aging.Apoptosis. 22,777-785. https://doi.org/10.1007/s10495-017-1374-2 ( 2017).

14. Wang, L. L. et al.. Study on the effect of reactive oxygen species-mediated oxidative stress on the activation of mitochondrial apoptosis and the tenderness of yak meat.Food Chem. 244,394-402. http://doi.org/10.1016/j.foodchem.2017.10.034 ( 2018)

15. Dirks, A. \& Leeuwenburgh, C. Apoptosis in skeletal muscle with aging. Am J Physiol Regul Integr Comp Physiol, 282, 519-527 https://doi.org/10.1152/ajpregu.00458.2001 (2002). 
16. Sergeeva, T. F. et al.. Relationship between intracellular pH, metabolic co-factors and caspase-3 activation in cancer cells during apoptosis.Biochimica et Biophysica Acta. 1864,604-611. https://doi.org/10.1016/j.bbamcr.2016.12.022 ( 2017 )

17. Shen, Q. W. et al. Pre-slaughter transport, AMP-activated protein kinase, glycolysis, and quality of pork loin. Meat Sci, 74, 388-395 https://doi.org/10.1016/j.meatsci.2006.04.007 (2006).

18. Boudjellal, A. et al. Is the $\mathrm{pH}$ drop profile curvilinear and either monophasic or polyphasic? Consequences on the ultimate bovine meat texture. Afr J Agr Res, 3, 195-204 https://doi.org/10.1021/bi00515a020 (2008).

19. Reshkin, S. J., Greco, M. R. \& Cardone, R. A. Role of pHi, and proton transporters in oncogene-driven neoplastic transformation. Philosophical transactions of the Royal Society of London, 369, 1-9 https://doi.org/10.1098/rstb.2013.0100 (2014).

20. Bai, Y. Q. et al.. Role of phosphorylation on characteristics of glycogen phosphorylase in lamb with different glycolytic rates post-mortem.Meat Sci. 164,108096. https://doi.org/10.1016/j.meatsci.2020.108096 (2020)

21. Zhao, K. X., Li, Y., Wang, Z. Q., Han, N. \& Wang, Y. Carnosine protects mouse podocytes from high glucose induced apoptosis through PI3K/AKT and Nrf2 pathways. Biomed Res Int. 2019, 4348973. https://doi.org/10.1155/2019/4348973 (2019)

22. Alexanne, C. et al. Loss of hepatic LRPPRC alters mitochondrial bioenergetics, regulation of permeability transition and trans-membrane ROS diffusion. Hum Mol Genet, 16, 3186-3201 https://doi.org/10.1093/hmg/ddx202 (2017).

23. Borutaite, V. \& Brown, G. C.. Mitochondrial regulation of caspase activation by cytochrome oxidase and tetramethylphenylenediamine via cytosolic cytochrome c redox state.J Biol Chem.282,31124-31130. https://doi.org/10.1074/jbc.M700322200 (2007)

24. Stadnik, J. \& Dolatowski, Z. J. Influence of sonication on Warner-Bratzler shear force, colour and myoglobin of beef ( $m$.semimembranosus). Eur Food Res Technol, 233, 553-559 https://doi.org/10.1007/s00217-011-1550-5 (2011).

25. Ke, R., Xu, Q., Li, C., Luo, L. Y. \& Huang, D. Q. Mechanisms of AMPK in the maintenance of ATP balance during energy metabolism. Cell Biol Int, 42, 384-392 https://doi.org/10.1002/cbin.10915 (2018).

26. Apaoblaza, A. et al. Glycolytic potential and activity of adenosine monophosphate kinase (AMPK), glycogen phosphorylase (GP) and glycogen debranching enzyme (GDE) in steer carcasses with normal (<5.8) or high (> 5.9) 24h pH determined in m. longissimus dorsi. Meat Sci, 101, 8389 https://doi.org/10.1016/j.meatsci.2014.11.008 (2015).

27. Ferguson, D. \& Gerrard, E. Regulation of post-mortem glycolysis in ruminant muscle. Anim Prod Sci, 54, 464-481 https://doi.org/10.1071/AN13088 (2014).

28. Chen, L., Li, Z., Everaert, N., Lametsch, R. \& Zhang, D. Q. Quantitative phosphoproteomic analysis of ovine muscle with different postmortem glycolytic rates. Food Chem, 280, 203-209 https://doi.org/10.1016/j.foodchem.2018.12.056 (2020).

29. Wang, Y. Y. et al. Comparison of activity, expression and S-nitrosylation of glycolytic enzymes between pale, soft and exudative and red, firm and non-exudative pork during post-mortem aging. Food Chem, 314, 126203 https://doi.org/10.1016/j.foodchem.2020.126203 (2020).

30. Zhu, Q. N., Xing, L. J., Hou, Q., Liu, R. \& Zhang, W. G. Proteomics identification of differential S-nitrosylated proteins between the beef with intermediate and high ultimate pH using isobaric iodoTMT switch assay. Meat Sci, 172, 108321 https://doi.org/10.1016/j.meatsci.2020.108321 (2020).

31. Deng, Y. et al. Relationship between thermal denaturation of porcine muscle proteins and water-holding capacity. J Food Sci, 67, 1642-1648 https://doi.org/10.1111/j.1365-2621.2002.tb08698.x (2002).

32. Abraham, A., Dillwith, J. W., Mafifi, G. G., VanOverbeke, D. L. \& Ramanathan, R.. Metabolite profile differences between beef longissimus and psoas muscles during display. Meat and Muscle Biology. 1, 18-27. http://doi.org/10.22175/mmb2016.12.0007 ( 2017 )

33. Pastsart, U., Boever, M. D., Claeys, E. \& Smet, S. D.. Effect of muscle and post-mortem rate of pH and temperature fall on antioxidant enzyme activities in beef.Meat Sci. 93,681-686. http://doi.org/10.1016/j.meatsci.2012.11.008 ( 2013)

34. Sun, X. B. et al. Effects of preslaughter shackling on post-mortem glycolysis, meat quality, changes of water distribution, and protein structures of broiler breast meat. Poultry Sci, 98, 4212-4220 https://doi.org/10.3382/ps/pez175 (2019).

35. Popp, J., Wicke, M., Klein, G. \& Krischek, C. The relationship of pork longissimus muscle pH to mitochondrial respiratory activities, meat quality and muscle structure. Animal, 9, 356-361 https://doi.org/10.1017/S1751731114002365 (2015).

36. Hekimi, S., Wang, Y. \& Noë, A.. Mitochondrial ROS and the effectors of the intrinsic apoptotic pathway in aging cells: The discerning killers!.Front Genet. 7,1-13. https://doi.org/10.3389/fgene.2016.00161 (2016)

37. Kurz, T., Terman, A. \& Brunk, U. T. Autophagy, ageing and apoptosis: The role of oxidative stress and lysosomal iron. Arch Biochem Biophys, 462, 220-230 https://doi.org/10.1016/j.abb.2007.01.013 (2007).

38. Sabharwal, S. S. \& Schumacker, P. T. Mitochondrial ROS in cancer: initiators, amplifiers or an Achilles' heel? Nat Rev Cancer, 14, 709-721 https://doi.org/10.1038/nrc3803 (2014).

39. Desagher, S. \& Martinou, J. C. Mitochondria as the central control point of apoptosis. Trends Cell Biol, 10, 369-377 https://doi.org/10.1016/S0962-8924(00)01803-1 (2000).

40. Yao, N. et al. B4G2 induces mitochondrial apoptosis by the ROS-mediated opening of $\mathrm{Ca}^{2+}$-dependent permeability transition pores. Cell Physiol Biochem, 37, 838-852 https://doi.org/10.1159/000430212 (2015).

Page $8 / 12$ 
41. Huang, M., Huang, F., Xu, X. \& Zhou, G. Influence of caspase-3 selective inhibitor on proteolysis of chicken skeletal muscle proteins during post mortem aging. Food Chem, 115, 181-186 https://doi.org/10.1016/j.foodchem.2008.11.095 (2009).

42. Suto, D., Sato, K., Ohba, Y., Yoshimura, T. \& Fujii, J. Suppression of the proapoptotic function of cytochrome c by singlet oxygen via a haem redox state independent mechanism. Biochem J, 392, 399-406 https://doi.org/10.1016/j.devcel.2009.07.022 (2005).

43. Zhao, M., Antunes, F., Eaton, J. W. \& Brunk, U. T. Lysosomal enzymes promote mitochondrial oxidant production, cytochrome c release and apoptosis. Eur J Biochem, 270, 3778-3786 https://doi.org/10.1046/j.1432-1033.2003.03765.x (2010).

44. Hou, Q., Liu, R., Tian, X. N., Zhang, W. G. \& Zhou, G. H. Involvement of protein S-nitrosylation in regulating beef apoptosis during postmortem aging. Food Chem, 326, 126975 https://doi.org/10.1016/j.foodchem.2020.126975 (2020).

45. Cao, J. et al. Morphological and biochemical assessment of apoptosis in different skeletal muscles of bulls during conditioning. J Anim Sci, 10, 3439-3444 https://doi.org/10.2527/jas.2009-2412 (2010).

46. Ouali, A. et al.. Biomarkers of meat tenderness: Present knowledge and perspectives in regards to our current understanding of the mechanisms involved.Meat Sci. 95,854-870. http://doi.org/10.1016/j.meatsci.2013.05.010 ( 2013)

47. Kemp, C. M. \& Parr, T.. Advances in apoptotic mediated proteolysis in meat tenderization.Meat Sci. 92,252-259. http://doi.org/10.1016/j.meatsci.2012.03.013 ( 2012)

48. Dransfield, E. Modelling post-mortem tenderisation-III: Role of calpain I in conditioning. Meat Sci, 31, 85-94 https://doi.org/10.1016/03091740(92)90074-E (1992).

49. Bhat, Z. F., Morton, J. D., Mason, S. L. \& Bekhit, A. E. A.. Role of Calpain System in Meat Tenderness: A Review.Food Sci Hum Well. 7,196-204. https://doi.org/10.1016/j.fshw.2018.08.002 (2018).

50. Lomiwesa, D., Farouka, M. M., Wu, G. \& Young, O. A. The development of meat tenderness is likely to be compartmentalised by ultimate pH. Meat Sci, 96, 646-651 https://doi.org/10.1016/j.meatsci.2013.08.022 (2014).

\section{Figures}

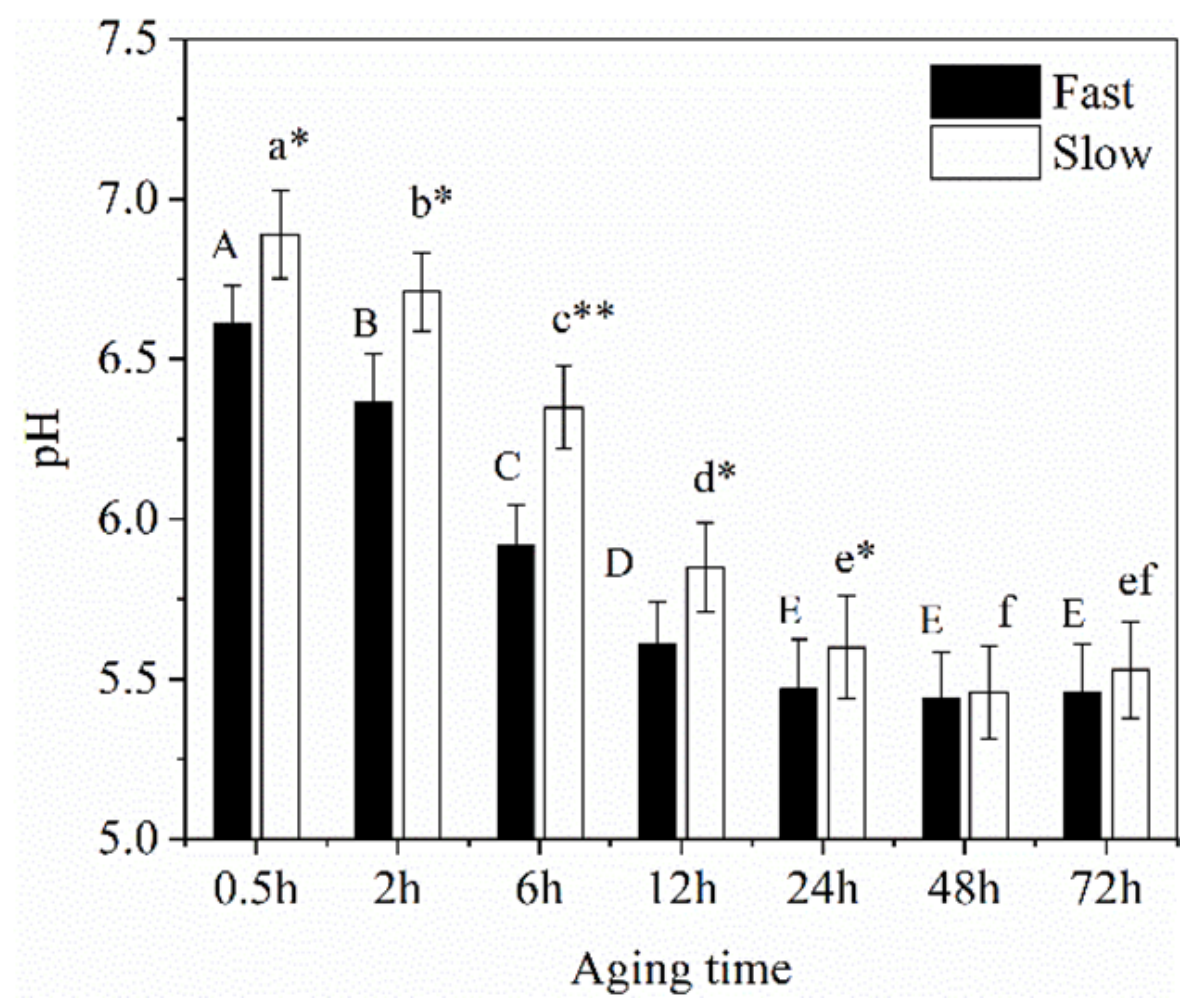

Figure 1

The $\mathrm{pH}$ in bovine muscles of different glycolytic rates at $0.5,2,6,12,24,48$, and $72 \mathrm{~h}$ postmortem. A-D: Each letter denotes a statistically significant difference in the fast group at different postmortem times $(P<0.05)$. a-e: Each letter denotes a statistically significant difference in the slow group at different postmortem times $(P<0.05)$. ${ }^{*}$ and $*$ indicate the significance compared the same time points between two groups $\left(* * P<0.01\right.$, $\left.{ }^{*}<0.05\right)$. Bars represent the standard error of mean. 

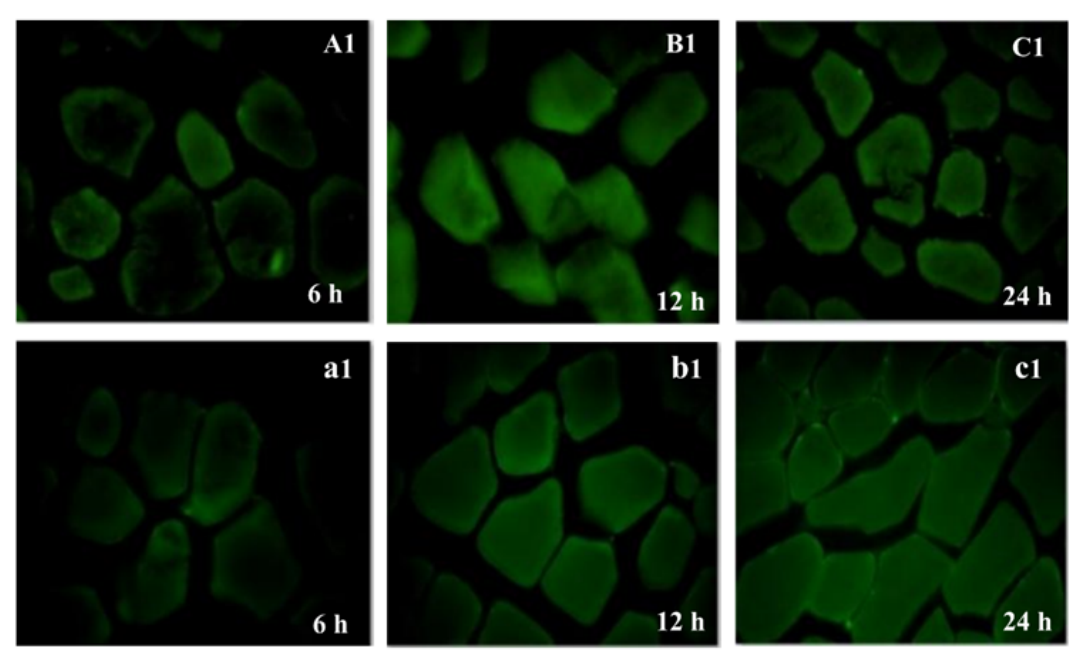

\section{a}

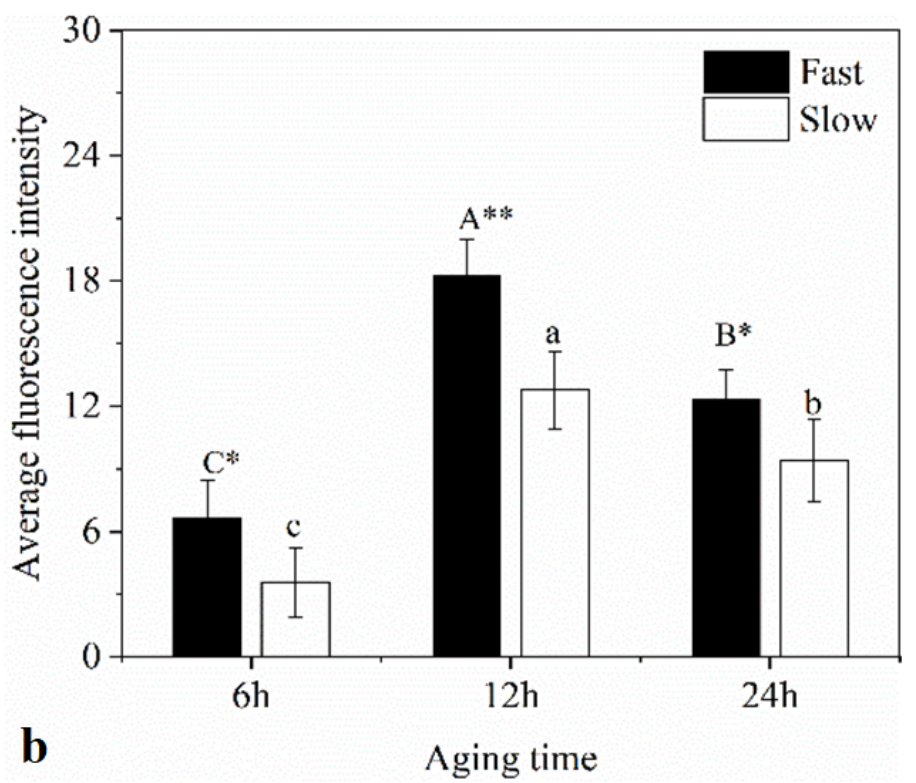

\section{Figure 2}

(A) Representative ROS immunofluorescence images of bovine muscles in the fast group (A1-C1) and the slow group (a1-c1) at 6, 12, and 24 $\mathrm{h}$ postmortem. (B) The average fluorescence intensity of ROS of muscle cell cross-sections in bovine muscles of different glycolytic rates at 6 , 12 , and $24 \mathrm{~h}$ postmortem. A-C: Each letter denotes a statistically significant difference in the fast group at different postmortem times $(P<0.05)$. a-c: Each letter denotes a statistically significant difference in the slow group at different postmortem times $(P<0.05)$. ** and * indicate the significance compared the same time points between two groups $\left(* * P<0.01,{ }^{*} \mathrm{P}<0.05\right)$. Bars represent the standard error of mean. 

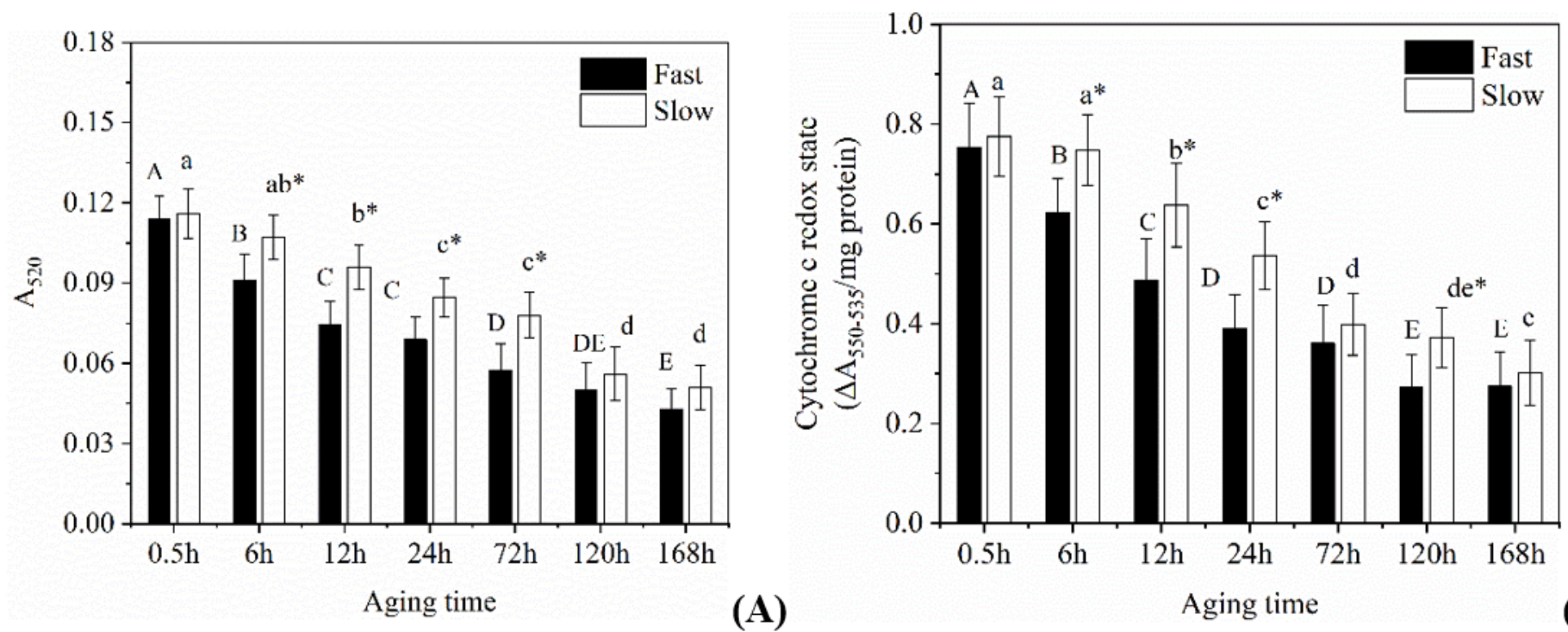

(B)

Figure 3

The mitochondrial membrane permeability (A) and the Cytochrome c reduction levels (B) in bovine muscles of different glycolytic rates at $0.5,6,12$, $24,72,120$, and $168 \mathrm{~h}$ postmortem. A-E: Each letter denotes a statistically significant difference in the fast group at different postmortem times $(P<0.05)$. a-e: Each letter denotes a statistically significant difference in the slow group at different postmortem times $(P<0.05)$ * indicates the significance compared the same time points between two groups $(P<0.05)$. Bars represent the standard error of mean.

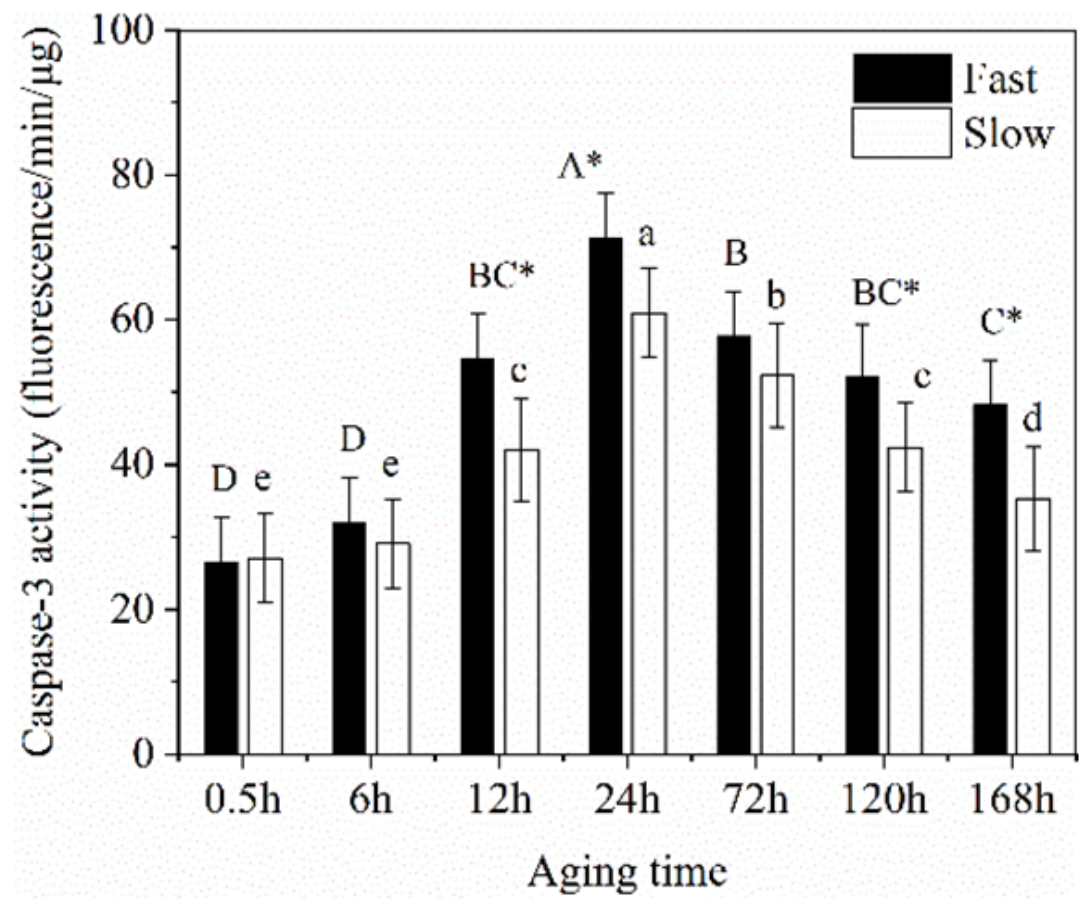

Figure 4

The caspase-3 activity in bovine muscles of different glycolytic rates at $0.5,6,12,24,72,120$, and $168 \mathrm{~h}$ postmortem. A-D: Each letter denotes a statistically significant difference in the fast group at different postmortem times $(P<0.05)$. a-e: Each letter denotes a statistically significant difference in the slow group at different postmortem times $(P<0.05)$. * indicates the significance compared the same time points between two groups $(P<0.05)$. Bars represent the standard error of mean. 


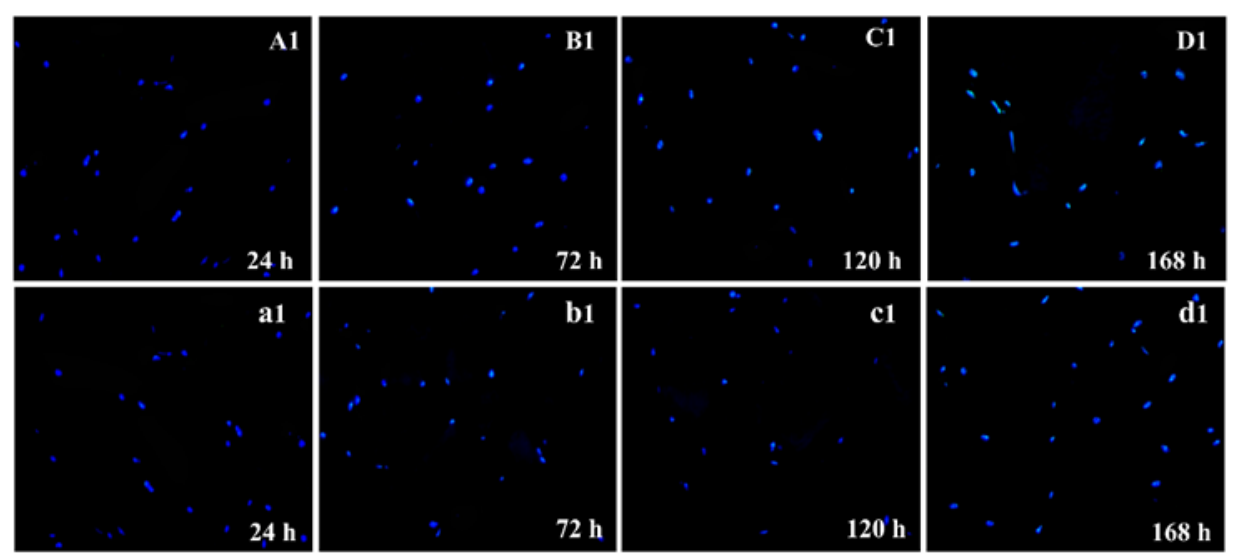

$\mathbf{a}$

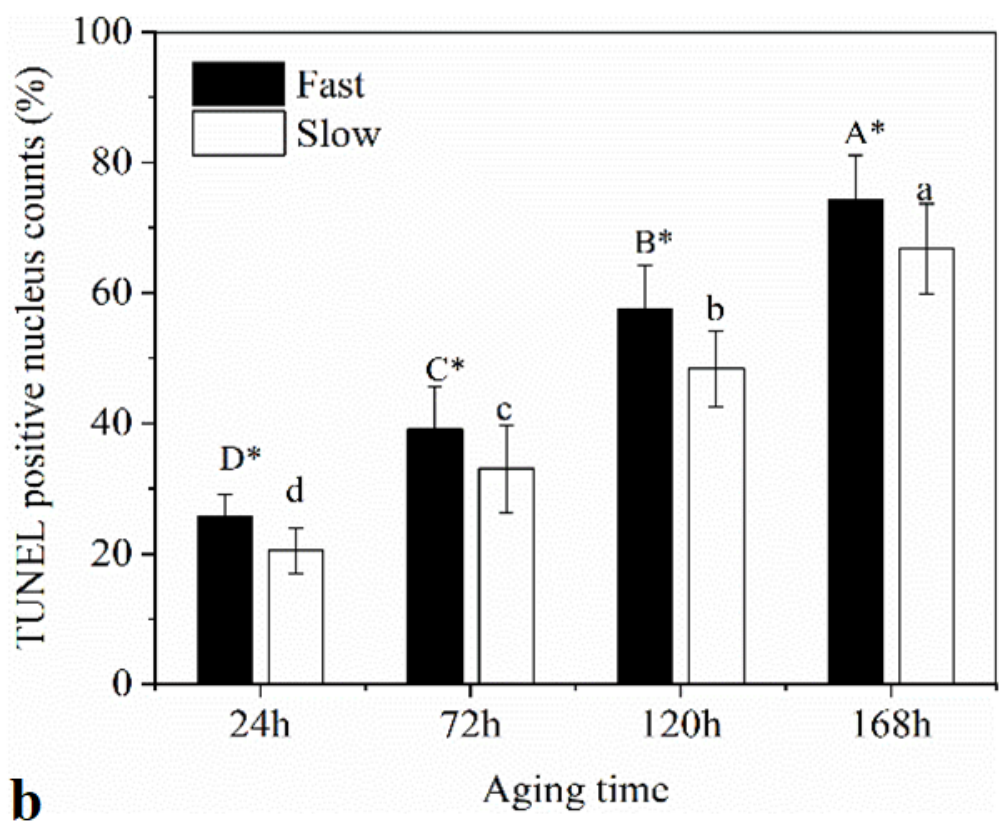

\section{Figure 5}

(A) Representative TUNEL positive nucleus images of bovine muscles in the fast group (A1-F1) and the slow group (a1-f1) at 24, 72, 120, and 168 h postmortem. Normal nuclei were labeled with blue fluorescence by adopting 4,6-diamidino-2-phenylindole (DAPI) dyes, whereas the apoptotic nuclei were labeled with green fluorescence through TUNEL. (B) The apoptosis rate in bovine muscles of different glycolytic rates at $24,72,120$, and $168 \mathrm{~h}$ postmortem. A-D: Each letter denotes a statistically significant difference in the fast group at different postmortem times $(P<0.05)$. a-d: Each letter denotes a statistically significant difference in the slow group at different postmortem times $(P<0.05)$. * indicates the significance compared the same time points between two groups $(P<0.05)$. Bars represent the standard error of mean. 